\title{
The Role of Climate Sensitivity and Ocean Heat Uptake on AOGCM Transient Temperature Response
}

\author{
SARAH C. B. RAPER* \\ Climate Research Unit, University of East Anglia, Norwich, Norfolk, United Kingdom \\ JONATHAN M. GREGORY \\ Hadley Center for Climate Prediction and Research, Met Office, Bracknell, Berkshire, United Kingdom \\ Ronald J. STOUFFER \\ Geophysical Fluid Dynamics Laboratory/NOAA, Princeton University, Princeton, New Jersey
}

10 October 2000 and 16 July 2001

ABSTRACT

\begin{abstract}
The role of climate sensitivity and ocean heat uptake in determining the range of climate model response is investigated in the second phase of the Coupled Model Intercomparison Project (CMIP2) AOGCM results. The fraction of equilibrium warming that is realized at any one time is less in those models with higher climate sensitivity, leading to a reduction in the temperature response range at the time of $\mathrm{CO}_{2}$ doubling [transient climate response (TCR) range]. The range is reduced by a further $15 \%$ because of an apparent relationship between climate sensitivity and the efficiency of ocean heat uptake. Some possible physical causes for this relationship are suggested.
\end{abstract}

\section{Introduction}

Several coupled atmosphere-ocean general circulation models (AOGCMs) have simulated climate change due to anthropogenic emissions based on the observed evolution of the concentrations of greenhouse gases from the early industrial period to present and running into the future based on assumed emissions scenarios. The results of many of these have been collected together in the Intergovernmental Panel on Climate Change (IPCC) Data Distribution Centre (DDC) dataset (http://ipcc-ddc.cru.uea.ac.uk) and show a range of global mean temperature change and ocean thermal expansion by the end of the twenty-first century. However, the assumed future greenhouse gas concentrations for these experiments and the resulting forcing used to drive

\footnotetext{
* Current affiliation: Alfred Wegener Institute for Polar and Marine Research, Bremerhaven, Germany.

Corresponding author address: Dr. Sarah C. B. Raper, Climate Research Unit, University of East Anglia, Norwich, Norfolk, NR4 7TJ, United Kingdom.

E-mail: s.raper@uea.ac.uk
}

the models is not identical. This complicates the comparison of their results.

The second phase of the Coupled Model Intercomparison Project (CMIP2; http://www-pcmdi.llnl.gov/ $\mathrm{cmip} /$ ) offers a unique dataset providing the opportunity to compare the transient climate response of different AOGCMs to a common forcing; $1 \%$ year $^{-1}$ compound increase in $\mathrm{CO}_{2}$ concentration (Meehl et al. 1997, 2000). The length of the simulations is $80 \mathrm{yr}$. The available data comprise monthly mean time series of surface air temperature, precipitation, and sea level pressure and four 20-yr means of many other atmosphere and ocean fields. Here we are concerned with identifying the factors that govern the global mean surface temperature response. The results vary from model to model primarily because different models have different climate sensitivities and because they differ in the efficiencies with which they transfer heat into the ocean.

The climate sensitivity of an AOGCM is traditionally defined as the equilibrium global mean temperature change in response to a doubling of atmospheric $\mathrm{CO}_{2}$ concentration. Because of the long timescales associated with deep ocean equilibration, the direct calculation of coupled model equilibrium temperature change for dou- 
bled $\mathrm{CO}_{2}$ requires an extended simulation and a considerable commitment of computer resources. Only one such calculation has been performed to date (Stouffer and Manabe 1999). Given this, the climate sensitivity is usually estimated as the equilibrium temperature change due to $\mathrm{CO}_{2}$ doubling in an AGCM with a mixed layer ocean (e.g., Senior and Mitchell 1993).

The climate sensitivity evaluated by these methods is a measure of the strength of the feedbacks in the climate system in the steady-state double- $\mathrm{CO}_{2}$ climate. Using it to explain differences between the transient response of different AOGCMs depends on the assumption that the feedback strengths are independent of climate. More recently, a third method (described farther below) has been devised, which calculates feedback strengths from the output of transient AOGCM experiments. Murphy (1995) called the sensitivity derived by this method the effective climate sensitivity. The effective climate sensitivity is a measure of the strength of the feedbacks as the climate evolves. Watterson (2000) calculates the effective climate sensitivity from several experiments with different versions of an AOGCM. The results show considerable variability particularly near the beginning of the integrations when the change in temperature is small. Nevertheless he concludes that the effective climate sensitivity is approximately constant and typically close to the appropriate mixed layer experiment result.

However, in an experiment where the forcing is a $1 \%$ compounded increase in $\mathrm{CO}_{2}$ concentration until double $\mathrm{CO}_{2}$ and constant thereafter, results from the HadCM2 model show that the effective climate sensitivity increases from about $2.0^{\circ} \mathrm{C}$ near the beginning of the integration to about $3.8^{\circ} \mathrm{C}$ after $900 \mathrm{yr}$ (Raper et al. 2001). Senior and Mitchell (2000) suggest that time-dependent cloud feedbacks arising from interhemispheric temperature differences associated with the slower warming of the Southern Ocean are responsible for the time dependence of the effective climate sensitivity. The extent to which this result is model dependent needs to be quantified, but earlier and later versions of the Hadley Centre model show broadly similar characteristics (Murphy 1995; Mitchell et al. 1998).

The measure of the climate sensitivity used here is the effective climate sensitivity calculated from the 20$\mathrm{yr}$ mean data centered on the time of $\mathrm{CO}_{2}$ doubling. It is thus a measure of the strength of the feedbacks in the climate response to the CMIP2 forcing at a time of maximum signal-to-noise ratio.

In some cases, the control climate is not exactly in a steady state; this is shown by a nonzero heat flux into the ocean, and a slow drift in surface climate. On the assumption that the same underlying drift is present in both the control and perturbed experiments, climate changes throughout this paper are calculated as contemporaneous differences between results of the perturbed and control experiments, in the hope of cancelling out the drift. However, it should be noted that in comparisons using the results of four AOGCM perturbation experiments with the ECHAM-1/LSG model, Raper and Cubasch (1996) find that the timing of the adjustment in the perturbation experiments differs from that in the control experiment. This may be regarded as a warning that should be borne in mind when following the standard method adopted here.

\section{Global mean temperature and ocean heat content change results}

The global-average near-surface temperature changes, $\Delta T$, for a number of models from the CMIP2 dataset are shown in Fig. 1a for the four 20-yr mean time periods. The temperature change averaged over the $20 \mathrm{yr}$ centered at the time of $\mathrm{CO}_{2}$ doubling (year 70) is defined by Cubasch et al. (2001) as the Transient Climate Response (TCR). The range of the TCR for the models considered here is $1.31^{\circ}-2.15^{\circ} \mathrm{C}$; the object of this paper is to investigate the factors that determine the range. Figure $1 \mathrm{~b}$ shows the same results but categorized by model and ordered in descending magnitude of the climate sensitivity, which is generally according to descending magnitude of temperature change response. The corresponding results for the ocean heat content change are given in Fig. 1c. Note that high (low) temperature change tends to be associated with high (low) heat content change, but an anomalously high ocean heat uptake, such as shown by MRI1, is associated with a suppressed surface temperature change.

\section{The effect of different $\mathrm{CO}_{2}$ doubling forcing}

The individual AOGCMs used here have reported values ranging from 3.45 to $3.74 \mathrm{~W} \mathrm{~m}^{-2}$ (Table 1) for the radiative forcing of a doubling of the atmospheric $\mathrm{CO}_{2}$. The effect of this range on the response has been investigated using simple climate models. In the 1990 IPCC Assessment (Shine et al. 1990), the radiative forcing for a $\mathrm{CO}_{2}$ doubling, $\Delta Q_{2 \mathrm{x}}$, was given as $4.37 \mathrm{~W}$ $\mathrm{m}^{-2}$. However, this value is now considered too high since it does not include solar absorption by $\mathrm{CO}_{2}$ or the effect of stratospheric adjustment (Myhre et al. 1998). Myhre et al.'s best estimate for $\Delta Q_{2 x}$ is $3.71 \mathrm{~W} \mathrm{~m}^{-2}$. The effect of using lower $\Delta Q_{2 x}$ values in a simple model has been investigated by Wigley and Smith (1998). They noted two effects. The first is the effect of $\Delta Q_{2 x}$ on the relative forcing due to $\mathrm{CO}_{2}$ and non- $\mathrm{CO}_{2}$ gases (with the latter including aerosols). The second is the effect of $\Delta Q_{2 x}$ on the response time. The first effect influences the equilibrium warming, whereas the second does not. It is only the second effect that applies here, since the CMIP2 forcing is for $\mathrm{CO}_{2}$ alone. Using the same simple model (Wigley and Raper 1992; Raper et al. 1996) the range of $\Delta Q_{2 x}$ implies a spread of temperature change around the time of $\mathrm{CO}_{2}$ doubling of between $0.02^{\circ}$ and $0.09^{\circ} \mathrm{C}$ for a climate sensitivity of $1.5^{\circ}$ and $4.5^{\circ} \mathrm{C}$, respectively. The effect of different $\Delta Q_{2 x}$ on the spread 

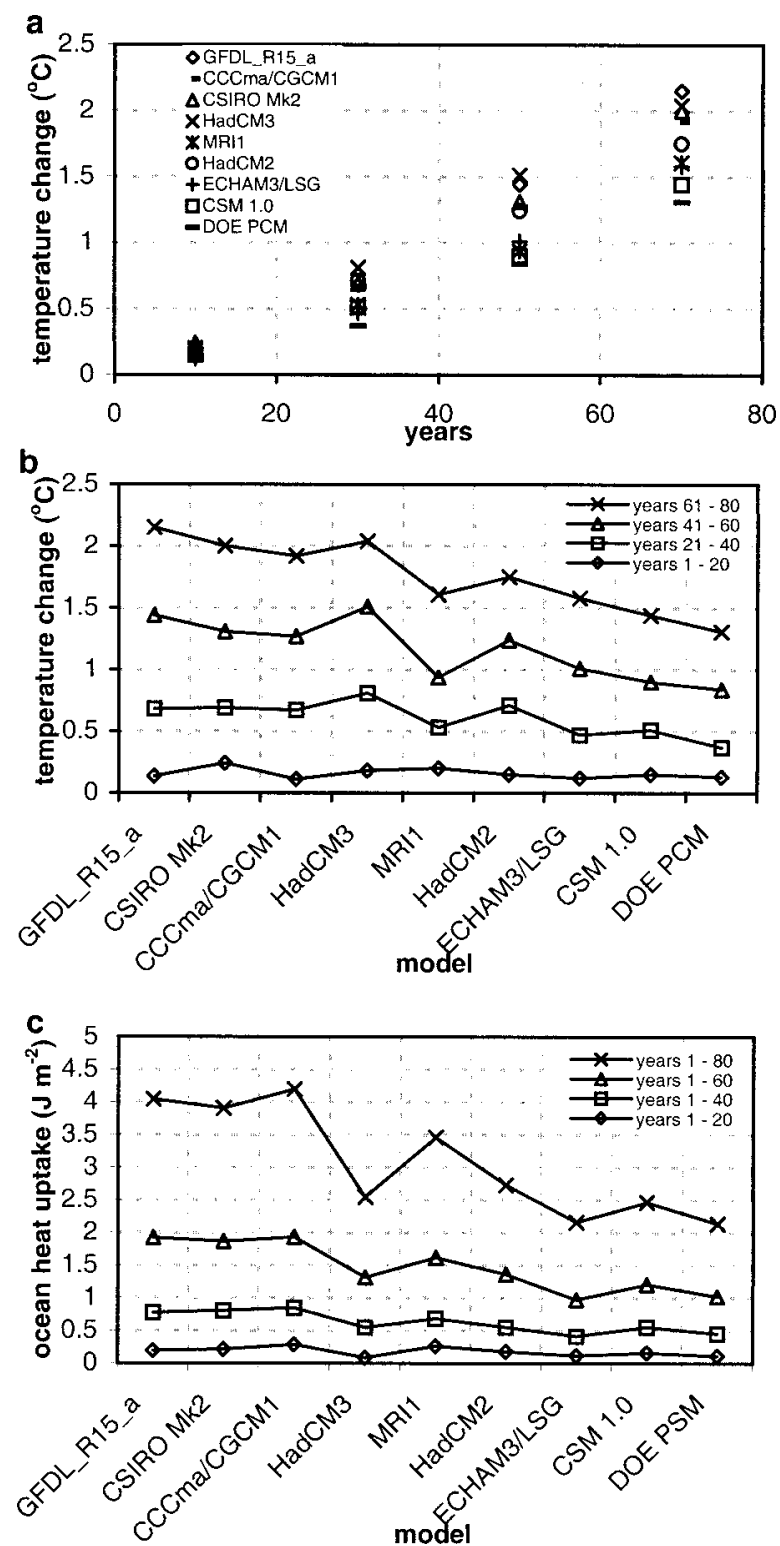

FIG. 1. The 20-yr mean model response for the $1 \%$ CMIP2 forcing experiments. (a) Time series of global mean near-surface air temperature change. (b) Temperature change categorized according to model. (c) Ocean heat content change categorized according to model.

of temperature changes given by the AOGCMs in Fig. 1 is therefore relatively small.

\section{Calculation of the effective climate sensitivity}

Climate experiments using AOGCMs give results that can be summarized by an energy balance equation of the form

$$
d \Delta H / d t=\Delta Q-\lambda \Delta T
$$

(Cubasch et al. 2001), where $\Delta H$ is the change in heat content of the climate system, $\Delta Q$ is the radiative forc- ing of the climate system, $\Delta T$ is the global average surface air temperature change, and $\lambda$ is the climate feedback parameter (e.g., Dickinson 1981; Wigley and Schlesinger 1985). The $\Delta$ terms represent changes with respect to the unperturbed climate state. This relation is useful because it applies for a wide range of magnitude of forcing and a variety of forcing agents (e.g., greenhouse gas, sulfate aerosol, solar). Since $\Delta Q$ is the forcing at the tropopause, $\Delta T$ is being used to represent the temperature change of the troposphere as a whole, and the term $\lambda \Delta T$ is the increase in radiative heat loss from the climate system due to climate change. For climate change over periods of years, changes in the heat content of the atmosphere, land, and cryosphere are very small compared with the change of heat content of the ocean, since the latter has almost all of the heat capacity of the system. To a good approximation, $d \Delta H /$ $d t$ is therefore equal to the heat flux $\Delta F$ into the ocean, when

$$
\Delta Q=\lambda \Delta T+\Delta F
$$

Thus, the radiative forcing is partitioned between increased heat loss to space and uptake of heat by the ocean.

At an equilibrium with doubled $\mathrm{CO}_{2}$, the radiative forcing is $\Delta Q_{2 x}$ and the net heat flux into the ocean $(\Delta F)$ is zero. Hence the feedback factor $\lambda$ is related to the traditional climate sensitivity $\Delta T_{2 \mathrm{x}}$ (discussed above) by the formula $\Delta T_{2 \mathrm{x}}=\Delta Q_{2 \mathrm{x}} / \lambda$. Since $\Delta Q, \Delta T$, and $\Delta F$ are known from the transient results, time-varying values of $\lambda$ can also be calculated and expressed as the effective climate sensitivity $\left(\Delta Q_{2 x} / \lambda\right)$ following Murphy (1995) and Gregory and Mitchell (1997).

We have calculated the effective climate sensitivities from the CMIP2 integrations $\left(1 \% \mathrm{yr}^{-1}\right.$ compound $\mathrm{CO}_{2}$ increase) for the four $20-y r$ periods. The values typically change over the comparatively short $80-\mathrm{yr}$ period. The effective climate sensitivities for the last 20 -yr average of the CMIP2 integrations, when the signal is strongest, generally agree well with the mixed layer sensitivities though there are exceptions (notably HadCM2). Confirming the validity of Eq. (2), we note that for this 20yr period in the CMIP2 results, the contribution of the ocean heat flux to changes in the heat content of the climate system is at least 2 orders of magnitude bigger than that of heat fluxes into the land and cryosphere together. In addition, Levitus et al. (2001) report that between the 1950s and 1990s the estimated increase of observed global ocean heat content is an order of magnitude bigger than any other component.

\section{The role of climate sensitivity and ocean heat uptake}

The effective climate sensitivity, the net ocean heat flux, and the surface temperature change for the various models are shown in Fig. 2a for the 20-yr mean values centered on the time of $\mathrm{CO}_{2}$ doubling. The model results 
TABLE 1. Values of model radiative forcing for a doubling of $\mathrm{CO}_{2}$ concentration after allowing for stratospheric adjustment. See CMIP2 (http://www-pcmdi.llnl.gov/cmip/) for model details.

\begin{tabular}{ccccccccccc}
\hline \hline AOGCM & GFDL & CGCM1 & CSIRO & HadCM2 & MRI1 & HadCM3 & ECHAM3 & CSM & PCM \\
\hline$Q_{2 \mathrm{x}}\left(\mathrm{W} \mathrm{m}^{-2}\right.$ & $3.71 *$ & $3.71 *$ & 3.45 & 3.47 & $3.71 *$ & 3.74 & $3.71 *$ & 3.45 & 3.45 & \\
\hline
\end{tabular}

* Value not available and therefore taken as the best estimate from Myhre et al. (1998).

are ordered in descending values of the effective climate sensitivity. Generally, the models with larger effective climate sensitivity also have larger net heat flux into the ocean. Now assume that

$$
\Delta F=\kappa \Delta T \text {. }
$$

This defines the "ocean heat uptake efficiency" $\kappa$ (Gregory and Mitchell 1997). Empirically, it is observed from climate model results that $\kappa$ varies with time (see Wigley and Schlesinger 1985). Nevertheless, $\kappa$ is a useful concept since for monotonically increasing forcing and not too near the beginning of an integration (when
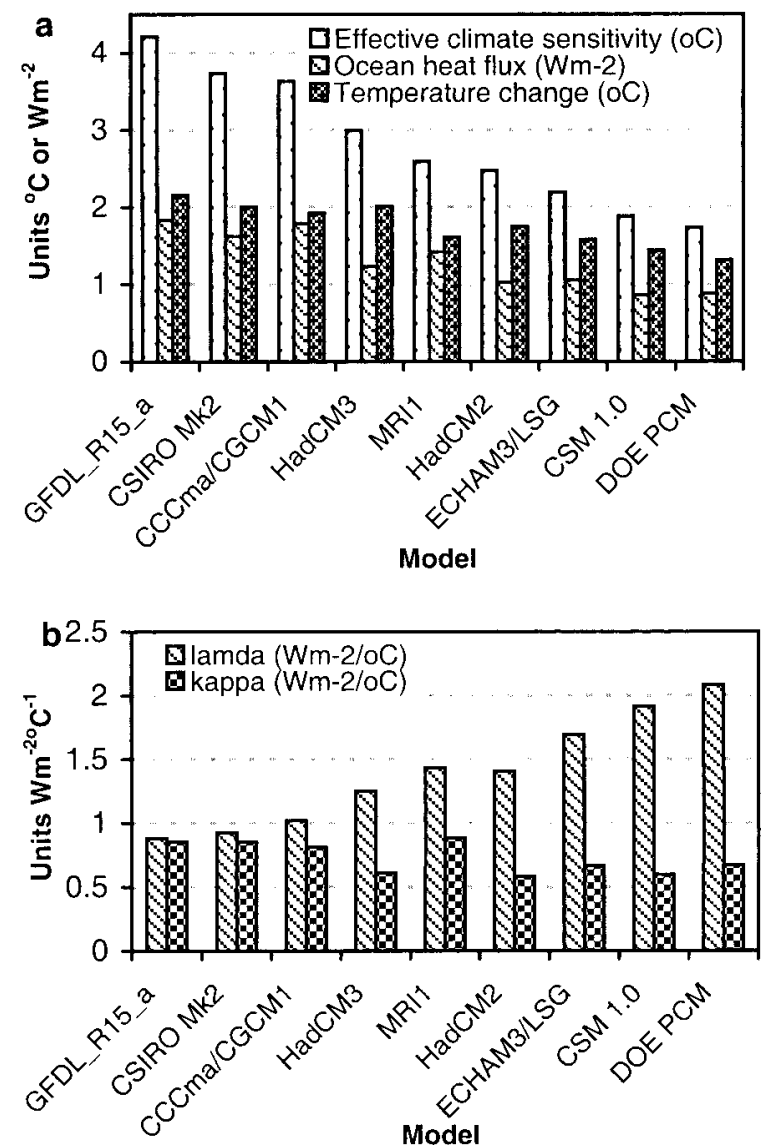

FIG. 2. Comparison of some CMIP2 model results for 20-yr average values centered on year 70 , the time of $\mathrm{CO}_{2}$ doubling. (a) Values are shown for the effective climate sensitivity, the net heat flux across the ocean surface multiplied by the ocean faction and the global mean temperature change. (b) Comparison of the feedback parameter $\lambda$ and the net heat flux across the ocean surface divided by the temperature change $\kappa$. mixed layer effects have an influence), $\kappa$ does not vary with time nearly as fast as $\Delta T$ so that a substantial part of the time variation of $\Delta F$ can be explained by the time variation $\Delta T$. Here we focus on the difference of $\kappa$ between the different models shown in Fig. $2 b$. We do not discuss further the time dependence of $\kappa$.

Using Eq. (3), Eq. (2) becomes

$$
\Delta Q=(\lambda+\kappa) \Delta T .
$$

At any given time, the equilibrium temperature change $\left(\Delta T_{e}\right)$ corresponding to forcing $\Delta Q$ can be defined by

$$
\Delta Q=\lambda \Delta T_{e} .
$$

Hence, the degree of disequilibrium or realized fraction of equilibrium warming is

$$
\Delta T / \Delta T_{e}=\lambda /(\lambda+\kappa) .
$$

If $\kappa$ is the same for all models, this means that $\Delta T / \Delta T_{e}$ is smaller for smaller $\lambda$ (i.e., higher sensitivity). This result was first shown by Hansen et al. (1984) and Siegenthaler and Oeschger (1984), and is explained in more detail by Wigley and Schlesinger (1985) and Hansen et al. (1985). An immediate consequence of Eq. (6) is that, when different models are compared, the spread of realized warmings at $2 \times \mathrm{CO}_{2}$ will be less than the spread of sensitivities. In fact, as will be shown below, the spread is even slightly smaller still when nonconstancy of $\kappa$ across models is accounted for.

\section{Effect of climate sensitivity and ocean heat uptake on the TCR results}

For the AOGCMs examined in this paper, the spread of effective climate sensitivities is given by the models DOE PCM and GFDL_R15_a, that is, $1.73^{\circ}-4.21^{\circ} \mathrm{C}$, a range $2.48^{\circ} \mathrm{C}$ wide. In Fig. $2 \mathrm{~b}$ we show the values of $\lambda$ and $\kappa$ for the individual models. Considering first the effect of ocean heat uptake assuming constancy of $\kappa$ across the models, we assume a midrange value $\kappa$ of $0.72 \mathrm{~W} \mathrm{~m}^{-2}{ }^{\circ} \mathrm{C}^{-1}$. Using Eq. (4) the TCR range is then $1.29^{\circ}-2.26^{\circ} \mathrm{C}\left(0.97^{\circ} \mathrm{C}\right.$ wide $)$. Heat uptake thus reduces the TCR range by a factor of about 2.5 relative to the range in effective climate sensitivity.

We observe that relatively small heat uptake efficiency (small $\kappa$ ) tends to be associated with relatively small effective climate sensitivity (large $\lambda$ ) (Fig. 2b). The TCR range for the models examined here is given by the combination of the low climate sensitivity (large $\lambda$ ) and low $\kappa$ of DOE PCM at one extreme, and the high climate sensitivity (small $\lambda$ ) and high $\kappa$ of GFDL_R15_a 
a

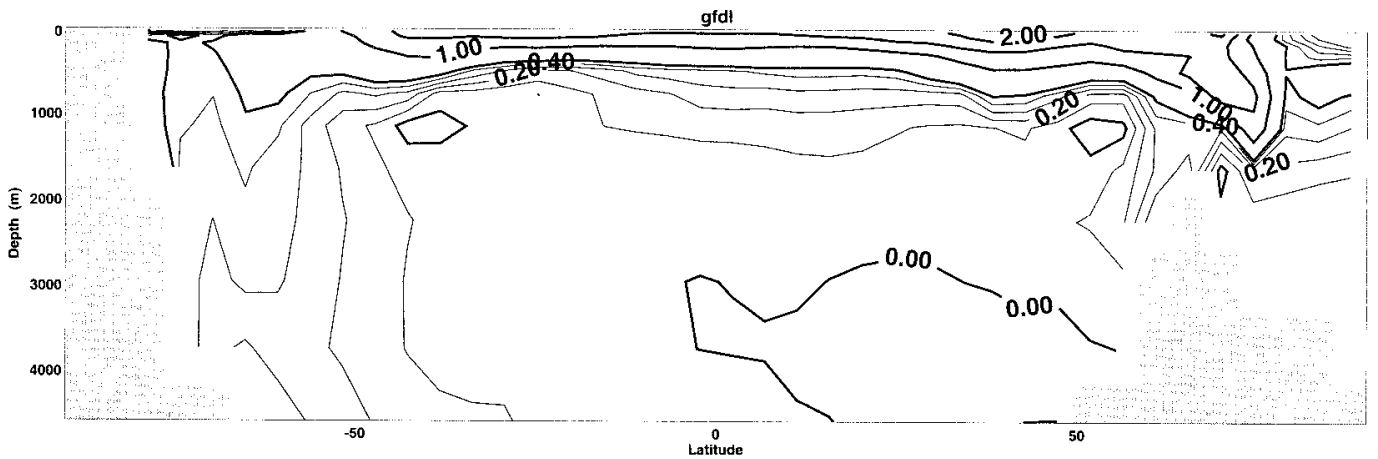

b

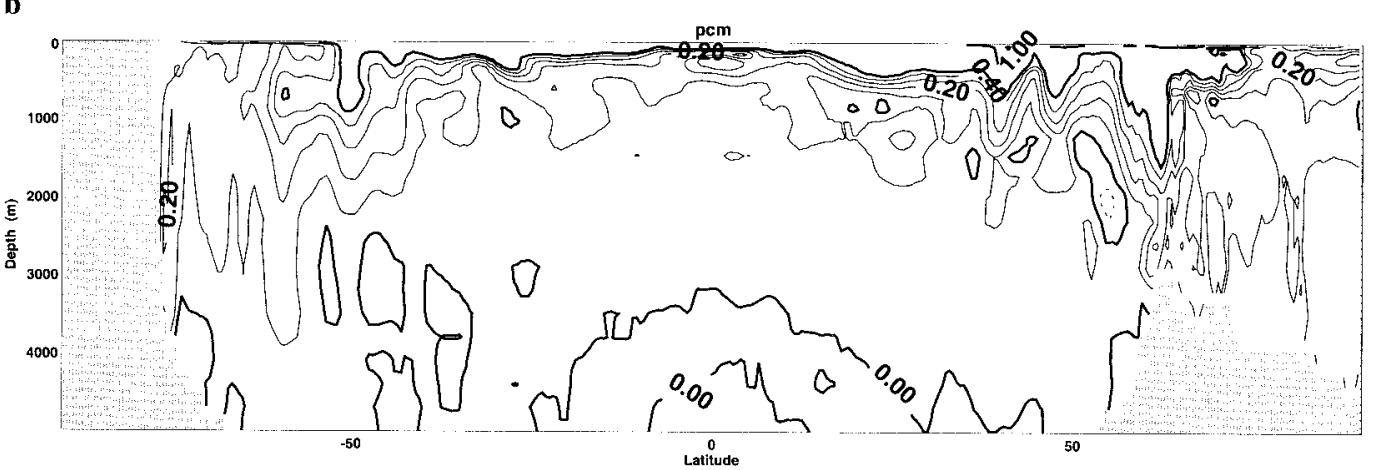

FIG. 3. Latitude-depth cross section of ocean temperature change for the $20 \mathrm{yr}$ about the time of $\mathrm{CO}_{2}$ doubling, for (a) the GFDL_R15_a model and (b) the DOE PCM model. The contour interval is $0.1^{\circ}$ below $0.5^{\circ} \mathrm{C}$ (thin lines) and $0.5^{\circ}$ above $0.5^{\circ} \mathrm{C}$ (thick lines). Negative values are shown as dashed lines.

at the other; namely, $1.31^{\circ}-2.15^{\circ} \mathrm{C}\left(0.84^{\circ} \mathrm{C}\right.$ wide $)$. This range is narrower by about $15 \%$ than the range given using a single $\kappa$ independent of $\lambda$. In terms of Eq. (4), the decrease in the range arises because the compensation between $\lambda$ and $\kappa$ restricts the variation of $(\lambda+$ $\kappa)$ and hence of $\Delta Q_{2 x} /(\lambda+\kappa)$.

\section{Discussion of a possible mechanism for the apparent relationship between $\lambda$ and $\kappa$}

The correlation coefficient between the nine values of $\lambda$ and $\kappa$ is -0.61 , which given the small sample size can only be considered significant with $90 \%$ confidence. This leaves room for the possibility that the apparent relationship could be a chance artifact of the different ocean model's subgrid-scale parameterizations, which can affect the ocean heat uptake (Weaver and Wiebe 1999). Alternatively, there may be a real physical cause of the relationship between $\lambda$ and $\kappa$. This could originate either from differences between the models or from nonlinearity within the models. Therefore we consider briefly how heat uptake occurs.

The oceans take up heat in low latitudes and transport it to high latitudes where they give up the heat to the atmosphere. When the climate warms, the ocean's surface becomes warmer and the water column tends to become more stable because warmer water is generally lighter than colder water. In high latitudes, vertical sta- bility is further enhanced by the increase of freshwater supply at the ocean surface. This results from an increase in the water vapor transport to high latitudes in the atmosphere, which in turn is a consequence of the ability of the warmer atmosphere to hold more water vapor. In high latitudes, the increased stability of the oceans resulting from surface warming and freshening inhibits heat loss from the interior of the ocean [by convection and upward diffusion along surfaces of constant density; Osborn (1998); Gregory (2000)]. This results in a warming through a deep layer of the highlatitude oceans as seen for the two models shown in Fig. 3. These results are representative of the oceanic temperature response found in all coupled models. The reduction of high-latitude heat loss from the ocean is equivalent to a net uptake of heat by the world ocean. An explanation for our results could be that high-latitude warming is greater relative to the global mean in models with high climate sensitivity. Alternatively, the ocean heat uptake within each model may be nonlinearly dependent on temperature change and thus most pronounced in those models that have the largest surface warming.

The increased stability in the oceans is also associated with a decline in the strength of the thermohaline circulation, which most AOGCMs simulate in response to a global warming. The change in the strength of the thermohaline circulation characterized by the maximum 

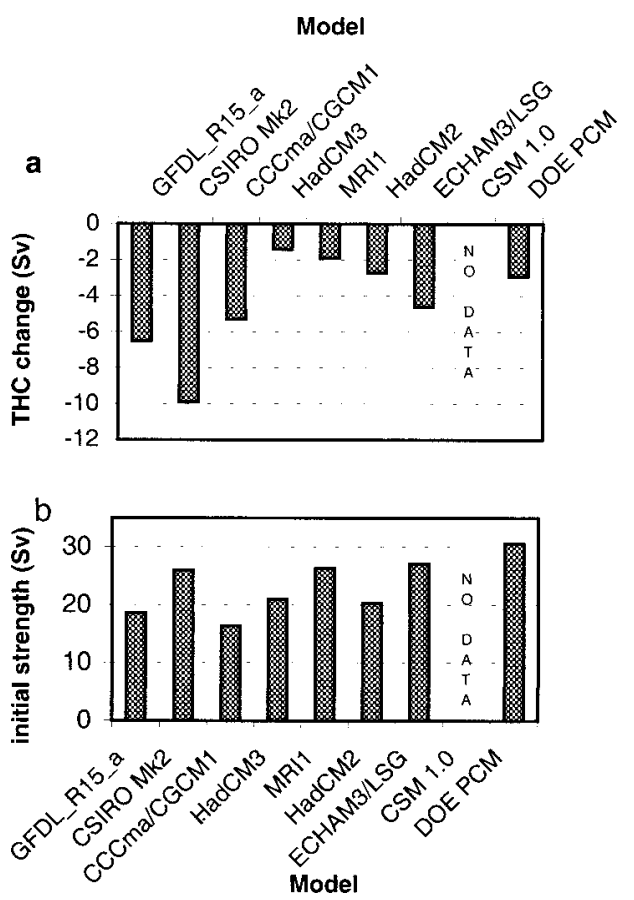

FIG. 4. Characteristics of the thermohaline circulation for the models studied. (a) Change in the maximum of the North Atlantic streamfunction for the $20 \mathrm{yr}$ about the time of $\mathrm{CO}_{2}$ doubling. (b) Initial strength of the North Atlantic streamfunction given as the contemporaneous value from the control run. Data for CSM 1.0 not available.

of the North Atlantic overturning streamfunction is shown in Fig. 4a for the $20 \mathrm{yr}$ centered on the time of $\mathrm{CO}_{2}$ doubling; Fig. 4b shows its strength in the corresponding period of the control. The three models with the highest climate sensitivities show the largest decline in the strength of the circulation. The hierarchy of climate models from simple upwelling diffusion models (Raper et al. 2001), through intermediate complexity models (Knutti and Stocker 2000) to AOGCMs (Gregory 2000; R. J. Stouffer 2000, personal communication) show an increase in ocean heat uptake in response to a decline in the strength of the thermohaline circulation. The essential character of Fig. 4a is unchanged when the thermohaline circulation strength changes are expressed per degree of warming $\left(\mathrm{Sv}^{\circ} \mathrm{C}^{-1}\right)$. Changes in the thermohaline circulation thus represent a related mechanism by which $\lambda$ and $\kappa$ could be related.

\section{Conclusions}

Comparison of CMIP2 results confirm that, for a given forcing, climate sensitivity remains the most important factor contributing to uncertainty in transient climate change predictions. The models examined have a climate sensitivity in the range $1.7^{\circ}-4.2^{\circ} \mathrm{C}$, expressed as the effective climate sensitivity near the time of $\mathrm{CO}_{2}$ doubling. Our analysis also confirms that, with a monotonic increase in forcing, the fraction of equilibrium warming that is realized at any one time is less in those models with higher climate sensitivity. As a first approximation, the range of the TCR can be obtained using the mean value for the ocean heat uptake efficiency $\kappa$, ignoring intermodel ocean heat uptake efficiency differences. As a second-order effect, differences in $\kappa$ across the models further reduce the range of the TCR by about $15 \%$, giving a range of $1.3^{\circ}-2.3^{\circ} \mathrm{C}$. A physical explanation of the relationship of $\kappa$ to the climate feedback factor could originate from differences between the models in the high-latitude amplification of global warming, from differences in the sensitivity of the thermohaline circulation to climate change, or from nonlinear processes common to the models.

Acknowledgments. This work was supported by the U.K. Department of the Environment, Transport and the Regions under Contract EPG/1/1/115 and Contract PECD/7/12/37. Sarah Raper was supported by the HGF Strategiefonds-Projekt 2000/13 SEAL Project. The authors thank the Program for Climate Model Diagnosis and Intercomparison, Curtis Covey, and the CMIP2 participants for making the CMIP2 data available. Also thanks to George Boer for supplying additional CCCma/ CGCM1 control run data and to Tom Wigley for a detailed review that led to many improvements.

\section{REFERENCES}

Cubasch, U., and Coauthors, 2001: Projections of future climate change. Climate Change 2001: The Scientific Basis. Contribution of Working Group I to the Third Assessment Report of the Intergovernmental Panel on Climate Change, J. T. Houghton, et al., Eds., Cambridge University Press, 525-582.

Dickinson, R. E., 1981: Convergence rate and stability of oceanatmosphere coupling schemes with a zero-dimensional climate model. J. Atmos. Sci., 38, 2112-2120.

Gregory, J. M., 2000: Vertical heat transports in the ocean and their effect on time-dependent climate change. Climate Dyn., 16, 501515

- , and J. F. B. Mitchell, 1997: The climate response to $\mathrm{CO}_{2}$ of the Hadley Centre coupled AOGCM with and without flux adjustment. Geophys. Res. Lett., 24, 1943-1946.

Hansen, J., A. Lacis, D. Rind, G. Russell, P. Stone, I. Fung, R. Ruedy, and J. Lerner, 1984: Climate Sensitivity: Analysis of feedback mechanisms. Climate Processes and Climate Sensitivity, Geophys. Monogr., No. 29, Amer. Geophys. Union, 130-163.

—_, G. Russell, A. Lacis, I. Fung, D. Rind, and P. Stone, 1985: Climate Response Times: Dependence on climate sensitivity and ocean mixing. Science, 229, 857-859.

Knutti, R., and T. F. Stocker, 2000: Influence of the thermohaline circulation on projected sea level rise. J. Climate, 13, 19972001

Levitus, S., J. I. Antonov, J. Wang, T. L. Delworth, K. W. Dixon, and A. J. Broccoli, 2001: Anthropogenic warming of Earth's climate system. Science, 292, 267-270.

Meehl, G. A., G. J. Boer, C. Covey, M. Latif, and R. J. Stouffer, 1997: Intercomparison makes for a better climate model. Eos, Trans. Amer. Geophys. Union, 78, 445-446, 451.

$-, \ldots, \ldots, \ldots$, and ——, 2000: The Coupled Model Intercomparison Project (CMIP). Bull. Amer. Meteor. Soc., 81, 313318.

Mitchell, J. F. B., T. C. Johns, and C. A. Senior, 1998: Transient response to increasing greenhouse gases using models with and 
without flux adjustment. Hadley Centre Tech. Note 2, Met Office, Bracknell, Berkshire, United Kingdom, 269 pp.

Murphy, J. M., 1995: Transient response of the Hadley Centre coupled ocean-atmosphere model to increasing carbon dioxide. Part III: Analysis of global-mean response using simple models. J. Climate, 8, 496-514.

Myhre, G., E. J. Highwood, K. P. Shine, and F. Stordal, 1998: New estimates of radiative forcing due to well mixed greenhouse gases. Geophys. Res. Lett., 25, 2715-2718.

Osborn, T. J., 1998: The vertical component of epineutral diffusion and the dianeutral component of horizontal diffusion. J. Phys. Oceanogr., 28, 485-494.

Raper, S. C. B., and U. Cubasch, 1996: Emulation of the results from a coupled general circulation model using a simple climate model. Geophys. Res. Lett., 23, 1107-1110.

— T. M. L. Wigley, and R. A. Warrick, 1996: Global sea-level rise: Past and future. Sea-Level Rise and Coastal Subsidence, J. D. Milliman and B. U. Haq, Eds., Kluwer Academic, 11-46.

— I. J. M. Gregory, and T. J. Osborn, 2001: Use of an upwellingdiffusion energy balance model to simulate and diagnose A/ OGCM results. Climate Dyn., 17, 601-613.

Senior, C. A., and J. F. B. Mitchell, 1993: $\mathrm{CO}_{2}$ and climate: The impact of cloud parameterization. J. Climate, 6, 393-418.

, and _ 2000: The time-dependence of climate sensitivity. Geophys. Res. Lett., 27, 2685-2688.
Shine, K. P., R. G. Derwent, D. J. Weubbles, and J.-J. Moncrette, 1990: Radiative forcing of climate. Climate Change. The IPCC Scientific Assessment, J. T. Houghton, G. J. Jenkins, and J. J. Ephraums, Eds., Cambridge University Press, 41-68.

Siegenthaler, U., and H. Oeschger, 1984: Transient temperature changes due to increasing $\mathrm{CO}_{2}$ using simple models. Ann. Glaciol., 5, 153-159.

Stouffer, R. J., and S. Manabe, 1999: Response of a coupled oceanatmosphere model to increasing atmospheric carbon dioxide: Sensitivity to the rate of increase. J. Climate, 12, 2224-2237.

Watterson, I. G., 2000: Interpretation of simulated global warming using a simple model. J. Climate, 13, 202-215.

Weaver, A. J., and E. C. Wiebe, 1999: On the sensitivity of projected oceanic thermal expansion to the parameterisation of sub-grid scale ocean mixing. Geophys. Res. Lett., 26, 3461-3464.

Wigley, T. M. L., and M. E. Schlesinger, 1985: Analytical solution for the effect of increasing $\mathrm{CO}_{2}$ on global mean temperature. Nature, 315, 649-652.

_- and S. C. B. Raper, 1992: Implications for climate and sea level of revised IPCC emissions scenarios. Nature, 357, 293300.

, and S. J. Smith, 1998: Uncertainties in projections of future global-mean temperature change. Do We Understand Global Climate Change? Norwegian Academy of Technological Sciences (NTVA), 185-195. 